\title{
Oral cancer knowledge and awareness among dental students
}

\author{
Tânderson Rittieri Camêlo Soares ${ }^{1}$, Maria Eugênia de Almeida Carvalho ${ }^{1}$, Lucielma Salmito Soares Pinto ${ }^{1,2}$, \\ Carlos Alberto Falcão ${ }^{1,3}$, Francisca Tereza Coelho Matos ${ }^{1}$, Tanit Clementino Santos ${ }^{1}$ \\ ${ }^{1}$ Centro Universitário UNINOVAFAPI, Dental School, Department of Diagnosis and Clinical Dentistry, Teresina, PI, Brasil \\ ${ }^{2}$ Universidade Estadual do Piauí - UFPI, Medical School, Department of Basic Sciences, Teresina, PI, Brasil \\ ${ }^{3}$ Universidade Estadual do Piauí - UFPI, Dental School, Department of Diagnosis and Clinical Dentistry, Parnaíba, PI, Brasil
}

Received for publication: January 31, 2014 Accepted: March 11, 2014

Correspondence to: Tanit Clementino Santos Centro Universitário de Saúde, Ciências Humanas e Tecnológicas do Piauí UNINOVAFAPI - Faculdade de Odontologia

Rua Vitorino Orthigues Fernandes, 6123, Bairro Uruguai - CEP: 64.073-505

Teresina, PI, Brasil

Phone: +55 8621060712

E-mail:tsantos@uninovafapi.edu.br

\begin{abstract}
Aim: To assess the knowledge and attitude of undergraduate dental students about oral cancer. Methods: A cross-sectional, quantitative study was conducted based on a questionnaire containing 15 questions about prevention, clinical aspects, and attitudes towards oral cancer. One hundredthirty-three undergraduate dental students between the second and fifth years were enrolled. The statistical significance was measured by Pearson's chi-square test. Results: There was a predominance of females $(58.65 \%)$ and most students were between 20 and 30 years of age $(75.19 \%)$. The risk factors for oral cancer mainly described by the students were smoking $(92.48 \%)$ and drinking $(84.21 \%)$. Squamous cell carcinoma was described as the most common type of oral cancer by $48.12 \%$ of the students. As much as $53.38 \%$ of the participants considered the tongue as the most affected anatomic region, $57.89 \%$ reported ulcers as the most frequent clinical aspect, and $44.36 \%$ attributed a firm and painless aspect to the regional metastatic lymph nodes. Most students reported regularly conducting a thorough examination of the oral cavity $(81.95 \%)$. Two of the 15 variables showed differences between the students, according to the school time: previous head and neck carcinoma (Pearson's chi-square, $p=0.03$ ) and guidance on the discontinuation of harmful habits (Pearson's chi-square, $p=0.02$ ). Conclusions: Students have a good knowledge of the etiology of oral cancer and are apparently alert in their examinations. The clinical aspects of the oral carcinoma, however, are not so clear. The difference regarding knowledge and attitudes towards oral cancer was minimal when different undergraduate years were considered. It is necessary to implement the clinical suspicion of oral cancer throughout the undergraduate course to enable awareness and early diagnosis.
\end{abstract}

Keywords: oral cancer; health knowledge, attitude, practice; education, dental.

\section{Introduction}

The incidence of oral cancer is rising in most countries, especially in developing countries $^{1-3}$. In Brazil, a nation-wide estimate for 2014 is 576,580 new cancer cases, about 15,000 affecting only the mouth, involving 11,280 men and 4,010 women. In the general male population, oral cancer is the fifth most frequent, and in northeastern Brazil (7.16 cases per 100 thousand) it is the fourth ${ }^{4}$. Squamous cell carcinoma (SCC) accounts for $95 \%$ of oral cancers and, in addition to being associated with avoidable etiological risk factors, it affects the tissue lining of the mouth, which is perfectly visible to dentists during routine examination ${ }^{3,5}$.

Although there is easy access for examination of the oral cavity, around 60\% of oral cancer cases are detected at later stages (III and IV). Despite therapeutic 
advances in recent years, this type of cancer has very poor survival rates worldwide, average of five-year survival rate of $50 \%$. Variables such as comorbidities, nutritional or immune status, tumor sites, and oncogene expressions are reported, but the stage at diagnosis remains the most important prognostic indicator for oral cancer. The higher the stage, the worse the prognosis ${ }^{8}$. Deficiencies in training, which hinder the recognition of lesions, contribute to the delayed diagnosis ${ }^{2,5}$.

The early diagnosis is essential to achieve the best results. It reduces rates of morbidity, mortality and mutilation, increases the quality of life and lowers treatment costs. To achieve this, it is important that health professionals, especially dentists, perform oral cancer examinations as part of their clinical practice and be especially aware of not only the pathogenesis of the disease, but also the first clinical signs ${ }^{6-7}$.

It is expected that dentists, on top of having an extensive understanding of the etiology of oral and clinical aspects of cancer, feel able to make a prompt diagnosis of this condition. Nevertheless, some studies have suggested that these professionals are not able to adequately detect oral cancer in its early stages due to their ineffective attitudes and lack of knowledge ${ }^{1}$. Additionally, information regarding the performance of dental students on this issue tends to be limited and unsatisfactory ${ }^{1-3,5,9-10}$. Thus, the aim of this study is to investigate the knowledge of dental students regarding the risk factors, clinical aspects and their attitudes about oral cancer.

\section{Material and methods}

This cross-sectional study was conducted at the Dental School of UNINOVAFAPI, Teresina, PI, Brazil. The 170 participants were second to fifth year undergraduate dental students. First-year students did not participate because oral pathology and semiology are not taught in the first year of graduation. The study was conducted between May and July 2013. The sample was obtained by simple random sampling, with a sampling error of 5\% and a confidence interval of $95 \%$, evenly distributed between the surveyed periods.

A questionnaire modified from Carter and $\operatorname{Ogden}^{3}$, and Dib et al. ${ }^{10}$, which contained 15 questions concerning knowledge and attitudes towards oral cancer, was applied to students at the end of the academic semester. The students received the questionnaire after agreeing to participate and giving written informed consent. The questionnaire was not used for graduation purposes, and the students were not compelled to fill it out. The study design received full approval from the institutional Research Ethics Committee (Protocol 0141.0.043.001-11).

The SPSS version 18.0 software (SPSS Inc., Chicago, IL, USA) was used, and the statistical significance was measured by the Pearson's chi-square test with significance level $\alpha$ of $5 \%$. For this test, students were divided into three groups: 1 (4th and 5th semesters), 2 (6th, $7^{\text {th }}$, and 8 th semesters) and 3 (9th and 10th semesters). Furthermore, dichotomy of multiple-choice questions with right and wrong categories was made.

\section{Results}

One hundred and seventy-seven questionnaires were applied and 133 were returned $(75.14 \%)$. There was a predominance of females $(58.65 \%)$ in the sample. Most students were between 20 and 30 years old $(75.19 \%)$, followed by students under 20 years of age $(22.56 \%)$ and older than 30 years $(2.25 \%)$. Regarding graduation, 44 (33.08\%) were in their 4th or 5th semesters (group 1), $56(42.11 \%)$ were between their 6th and 8th semesters (group 2), and 33 (24.81\%) students were in their last undergraduate year (group 3).

Risk factors for oral cancer were described as smoking and alcohol consumption by $92.48 \%$ and $84.21 \%$ of the students, respectively. In addition, a family history of head and neck cancer $(75.94 \%)$, solar radiation for cancer of the lip $(66.17 \%)$, previous head and neck cancer $(51.13 \%)$, and age $(28.57 \%)$ were also described as risk factors. Analyzing the factors according to the time of graduation, in general, only the factors of tobacco use and exposure to sunlight for carcinoma of the lip were more reported by more advanced students, while all others were generally described by initial graduate students (group 1). However, this difference was statistically significant only for the occurrence of previous carcinoma in the head and neck (Pearson's chi-squared, $\mathrm{p}=$ 0.03) (Table 1).

Analyzing the clinical features, $48.12 \%$ described the SCC as the most common type of oral cancer, $53.38 \%$ described tongue as the primary tumor site, $57.89 \%$ reported ulcer as the most frequent clinical aspect, and $44.36 \%$ considered painless firm lymph nodes as the main form of metastasis of these tumors. There was no statistically significant difference among the groups. However, in general, a slightly better pattern of response was observed among second-year students (group 1) (Table 2).

As to the attitudes of the undergraduates, $81.95 \%$ reported to regularly conduct thorough examination of the oral cavity, including soft tissues; $81.2 \%$ advise their patients about the dangers of alcohol and tobacco; $73.69 \%$ stated to be at least partially able to detect precancerous lesions, $69.19 \%$ refer the patient immediately to another professional when a suspicious lesion is identified, and $69.17 \%$ stated searching for cancer oral lesions in their examinations. Advanced students most often reported searching for cancer lesions, to be able to recognize precancerous lesions, rapid referral in suspected cases, and guidance to discontinue harmful habits, though only the latter conduct differed statistically between groups (Pearson's chi-square, $\mathrm{p}=0.02$ ) (Table 3).

\section{Discussion}

Due to the opportunity of routinely examining the oral cavity, the dentist has the chance to diagnose oral cancer even in asymptomatic patients before dissemination occurs to adjacent tissues. However, to make it actually effective, dentists must understand oral cancer as a public health problem. It is the responsibility of the dental schools to ensure 
Table 1 - Rate of students' answers to the questions concerning main risk factors and $\mathrm{p}$ value.

\begin{tabular}{|c|c|c|c|c|c|c|c|c|c|}
\hline \multirow[t]{2}{*}{ Variable } & \multirow[t]{2}{*}{ Answer } & \multicolumn{2}{|c|}{ Group 1} & \multicolumn{2}{|c|}{ Group 2} & \multicolumn{2}{|c|}{ Group 3} & \multicolumn{2}{|c|}{ Total } \\
\hline & & $\mathrm{n}$ & $\%$ & $n$ & $\%$ & $n$ & $\%$ & $n$ & $\%$ \\
\hline \multirow[t]{2}{*}{ Tabaco } & Yes & 39 & 88.64 & 52 & 92.86 & 32 & 96.97 & 123 & 92.48 \\
\hline & No & 5 & 11.36 & 4 & 7.14 & 1 & 3.03 & 10 & 7.52 \\
\hline \multirow[t]{2}{*}{ Alcohol } & Yes & 39 & 88.64 & 44 & 78.57 & 29 & 87.88 & 112 & 84.21 \\
\hline & No & 5 & 11.36 & 12 & 21.43 & 4 & 12.12 & 21 & 15.79 \\
\hline \multirow{2}{*}{$\begin{array}{l}\text { Head and } \\
\text { neck cancer } \\
\text { family } \\
\text { history }\end{array}$} & Yes & 34 & 77.27 & 42 & 75.00 & 25 & 75.76 & 101 & 75.94 \\
\hline & No & 10 & 22.73 & 14 & 25.00 & 8 & 24.24 & 32 & 24.06 \\
\hline \multirow[t]{2}{*}{ UV radiation } & Yes & 29 & 65.91 & 32 & 57.14 & 27 & 81.82 & 88 & 66.17 \\
\hline & No & 15 & 34.09 & 24 & 42.86 & 6 & 18.18 & 45 & 33.33 \\
\hline \multirow{2}{*}{$\begin{array}{l}\text { Previous } \\
\text { head and } \\
\text { neck cancer }\end{array}$} & Yes & 27 & 61.36 & 21 & 37.50 & 20 & 60.61 & 68 & 51.13 \\
\hline & No & 17 & 38.64 & 35 & 62.50 & 13 & 39.39 & 65 & 48.87 \\
\hline \multirow[t]{2}{*}{ Age } & Yes & 13 & 29.55 & 16 & 28.57 & 9 & 27.27 & 38 & 28.57 \\
\hline & No & 31 & 70.45 & 40 & 71.43 & 24 & 72.73 & 95 & 71.43 \\
\hline
\end{tabular}

*Pearson Chi-square.

Table 2 - Rate of students' answers to the questions concerning main clinical aspects of oral cancer and $\mathrm{p}$ value.

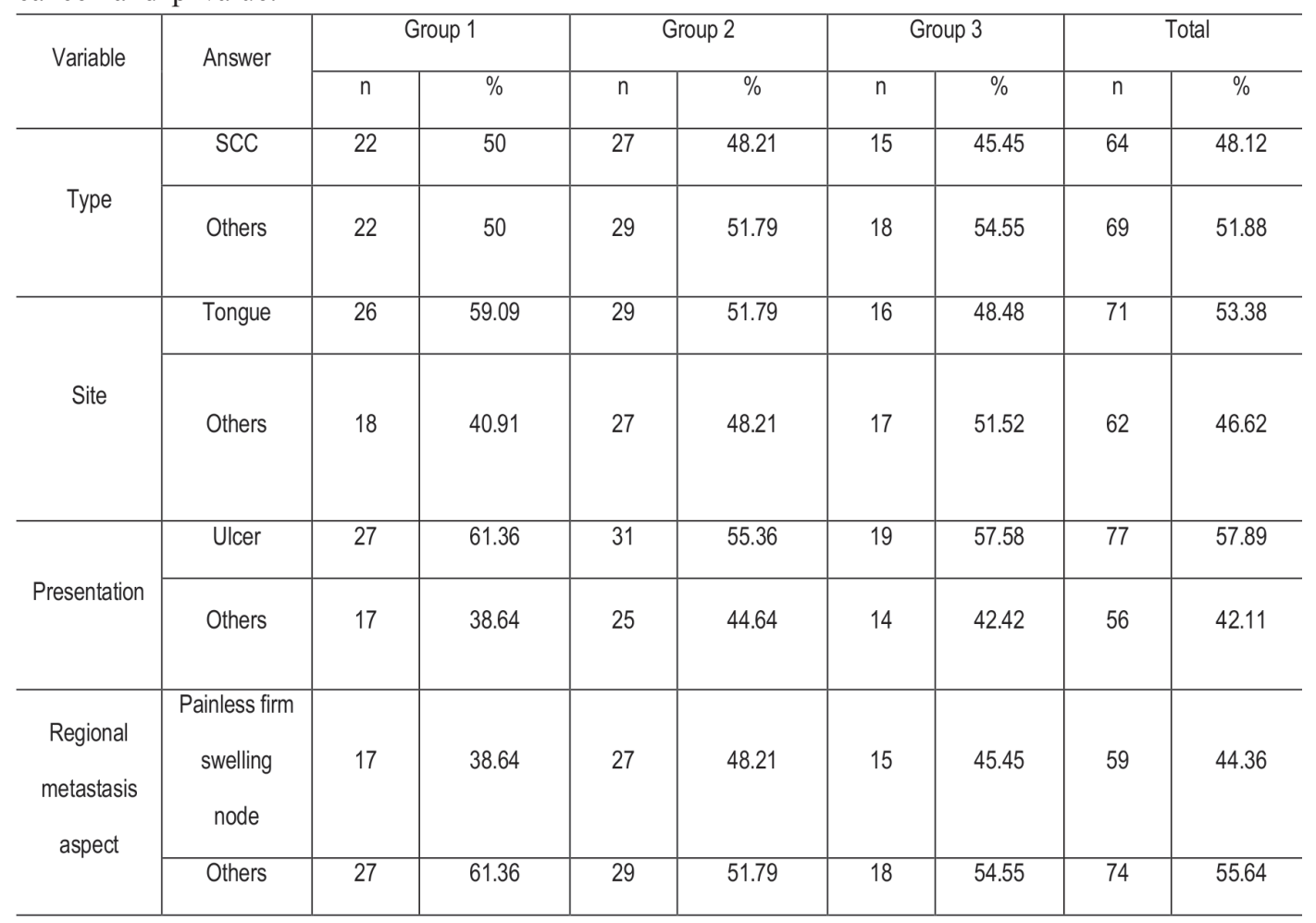

*Pearson Chi-square. SCC: Squamous cell carcinoma

the formation of a generalist with solid technical, scientific, humanistic, and ethical knowledge, aimed at promoting health, emphasizing the philosophy of prevention of prevalent oral diseases ${ }^{11}$. Although post-graduation are important for the activity in this field, graduation is essential and must ensure that students have the relevant basic knowledge on prevention and early diagnosis of oral cancer ${ }^{10}$.

The sample exhibited a large number of female $(58.65 \%)$ and young students between 20 and 30 years old $(75.19 \%)$. In Brazil, first-year undergraduate students are on average 25 years old. Half of them are up to 22 years old. Furthermore, there is a large female participation. At the start, $55.8 \%$ are 
Table 3 - Rate of students' answers to the questions concerning their clinical conducts and p value.

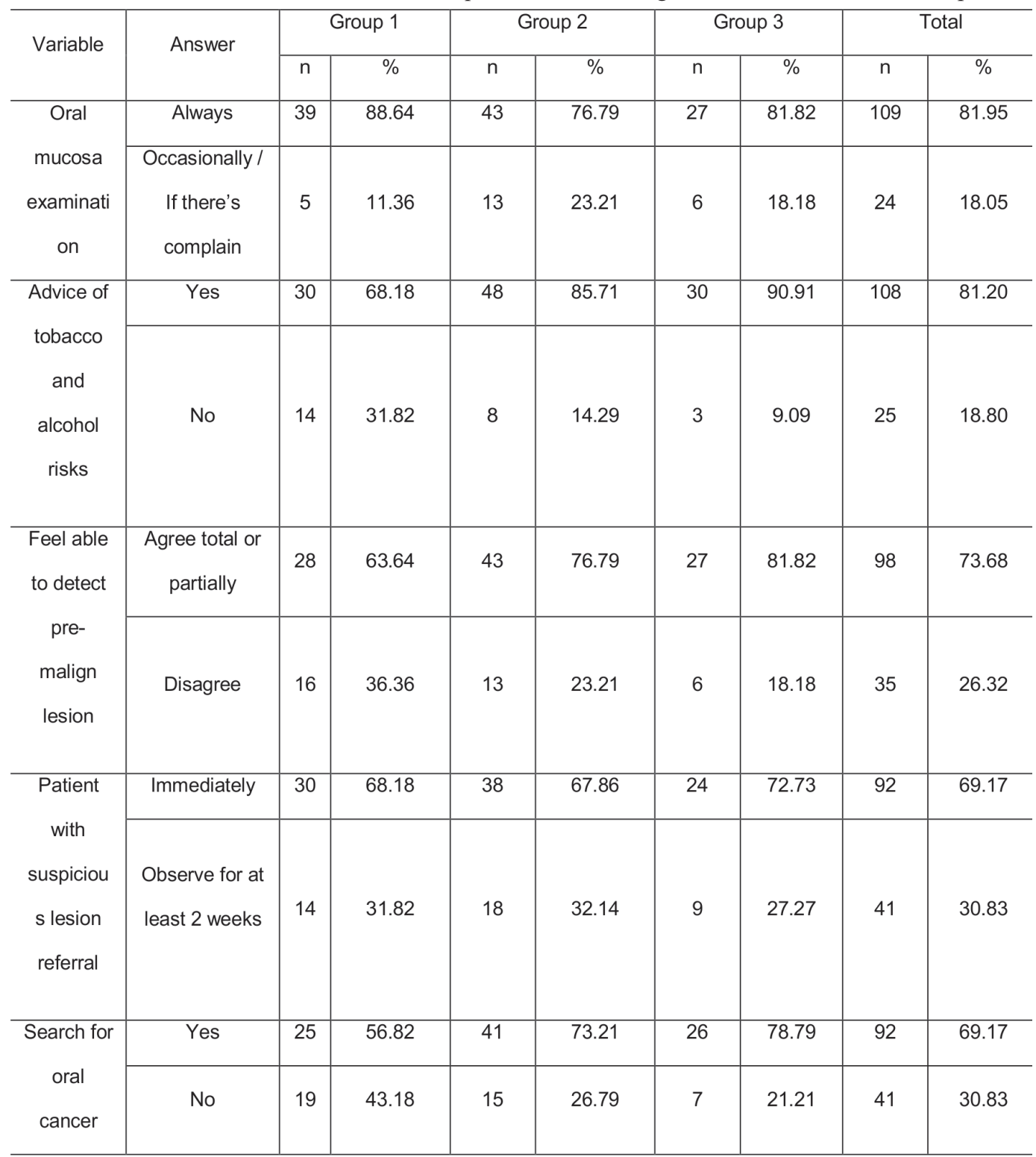

*Pearson Chi-square

women, and $61.1 \%$ of graduates are females as well ${ }^{12}$. This study had some limitations, such as being based on a selfapplied questionnaire, using students' own perceptions, and the limited number of questions. However, this methodology

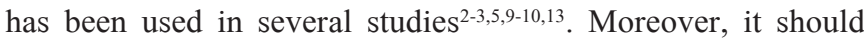
be considered that since the questionnaires were not used for graduation purposes, the results represent the actual situation of knowledge and behavior of students ${ }^{14}$.

Smoking and alcohol consumption were correctly mentioned as risk factors by $92.48 \%$ and $84.21 \%$ of the students, respectively. In addition, other factors were described, with decreasing percentages, including family history of head and neck cancer, ultraviolet (UV) radiation for cancer of the lip, previous cancer of the head and neck, and age. Oral cancer has a multifactorial etiology: genetic factors, tobacco, alcohol, UV radiation (lip cancer), papillomavirus (HPV), a diet poor in fruit and vegetables, history of cancer in the head and neck, and age may be listed as factors ${ }^{4,15-16}$.

While some authors have reported no significant relationship between the risk of oral cavity cancer and family history of non-head and neck cancers ${ }^{17}$, others have mentioned a higher risk of oral and pharyngeal cancer in subjects with a family history of cancers like lung carcinoma and skin melanoma $^{18}$ or first-degree relative history of cancers at any site $^{19}$. Nevertheless, most of them agree that a higher risk of oral cancer is observed among subjects that have first-degree relatives with head and neck cancer history compared with subjects without such a family history ${ }^{16-18}$. Genetic polymorphism of genes involved in the metabolism of tobacco and alcohol carcinogens and DNA repair may explain familial clustering of cancer cases, but it may also reflect a family tendency of similar behavior concerning alcohol and tobacco ${ }^{17}$. 
The literature however, is unanimous in pointing out that the main risk factors are exposure to tobacco carcinogens and excessive alcohol consumption ${ }^{20}$. The percentage of accuracy of the present study showed a good level of knowledge of the relationship between these factors and oral cancer, especially the frequency of smoking and drinking alcohol, which were similar ${ }^{3,10}$ or even better than those seen in other studies with dental undergraduates ${ }^{2,5,13}$.

About the clinical characteristics, only $48.12 \%$ of students correctly described SCC as the most common type of oral cancer. A little more than half of the students indicated the tongue as the main site and ulcerated lesion as the primary clinical aspect, $53.38 \%$ and $57.89 \%$, respectively. The pattern of responses was shown to be unsatisfactory, as SCC corresponds to 90 to $95 \%$ of oral cancers. Despite occurring anywhere in the oral cavity, the posterolateral border of the tongue is most usually affected and among the possible clinical aspects worth mentioning the presence of solitary chronic ulceration ${ }^{3,5,16}$. The fewer reports of ulcer appearance may be attributed to the great diversity of SCC forms ${ }^{10}$. In fact, the histopathological diagnosis of SCC has been done in leukoplakia, erythroplakia, exophytic, endophytic, verrucous or ulcerated forms ${ }^{4,16}$.

Only $44.36 \%$ considered the firm and painless lymph nodes as the main form of metastasis of these tumors. About $30 \%$ of patients clinically present a palpable metastatic lymph node, and an additional $25 \%$ will develop cervical metastases in at least two years ${ }^{16}$. Thus, it is essential that practitioners are aware of the importance of palpation and know how to recognize the pattern of neoplastic lymphadenopathy. The literature shows better results, in which a higher number of students said to recognize nodal metastases ${ }^{10,13}$, yet others show even worse results ${ }^{2}$.

The answers on the attitudes of students revealed that most of them reported to examine the oral cavity regularly $(81.95 \%)$, including soft tissues, and considered themselves as at least partially able to detect precancerous lesions (73.69\%). Similarly, other authors have observed that in general, students know that they should perform the clinical exam in the entire mouth, and despite variations of their confidence, the majority claim to be able to detect oral cancer ${ }^{10}$. Additionally, students $(81.20 \%)$ considered instructing patients about the dangers of alcohol and tobacco as important. In fact, at least three quarters of cases of oral cancer could be prevented by eliminating factors such as tobacco and alcohol ${ }^{16}$. Thus, it is important to disclose this type of information, since not doing so may be deemed negligent omission ${ }^{10}$.

Comparing the answers on the knowledge and attitudes of students according to the time of undergraduation, the results were similar, with minimal differences between groups. Only two of the fifteen variables examined presented statistically significant differences. As regards to knowledge, previous head and neck carcinoma was significantly more reported as a risk factor by second-year students, while respecting the conduct and guidance to withdrawn the deleterious habits was statistically more described by fourth- year students. Nevertheless, in general, the pattern exhibited slightly better response in four of the six analyzed risk factors, and in three of the four most frequent clinical variables of oral cancer from second year students. In relation to the conduct and attitudes, students of more advanced undergraduate years showed a little better response pattern in four of the five assessed behaviors. The findings of other authors corroborate the results of this study, showing that the knowledge of undergraduates in relation to oral cancer presented no significant difference over the years, despite the fact that increased confidence can be noted among the students in the last years ${ }^{5}$. This result could be due to the frequent concentration of curricular disciplines of oral pathology and semiology, which explains why the approaches to oral cancer are primarily restricted to second-year students in most dental schools in Brazil, leaving it as a second-plan matter in the subsequent years.

It may be concluded that students have a good knowledge of the etiology of oral cancer and are apparently alert in their examinations to the possibility of detecting malignant lesions. Nevertheless, it was noticed that the clinical features of the lesion are not sufficiently clear to the students. Additionally, the difference in relation to knowledge and attitudes towards oral cancer was minimal when different undergraduate years were considered. Thus, it is suggested that knowledge of oral cancer, in particular its clinical presentation, needs to be reinforced throughout the undergraduate dental course to enable raising suspicions and making an early diagnosis of lesions.

\section{References}

1. Jaber MA. Dental practitioner's knowledge, opinions and methods of management of oral premalignancy and malignancy. Saudi Dent J. 2011; 23: $29-36$

2. Oliveira JMB, Pinto LO, Lima NGM, Almeida GCM. Oral Cancer: Assessment of Academic Dentistry and Nursing Knowledge as for the Risk Factors and Diagnostic Procedures. Rev Bras Canc. 2013; 59: 211-8.

3. Carter LM, Ogden GR. Oral cancer awareness of undergraduate medical and dental students. BMC Med Educ. 2007; 15: 44-52.

4. Brazil. Ministry of Health. Cancer National Institute. Estimative 2014: cancer incidence in Brazil. Brasilia: Ministry of Health; 2013.

5. Ogden GR, Mahboobi N. Oral cancer awareness among undergraduate dental students in Iran. J Cancer Educ. 2011; 26: 380-5.

6. Gómez I, Warnakulasuriya S, Varela-Centelles PI, López-Jornet P, SuárezCunqueiro M, Diz-Dios $P$, et al. Is early diagnosis of oral cancer a feasible objective? Who is to blame for diagnostic delay? Oral Dis. 2010; 16: 333-42.

7. Baykul T, Yilmaz HH, Aydin U, Aydin MA, Aksoy M, Yildirim D. Early diagnosis of oral cancer. J Int Med Res. 2010; 38: 737-49.

8. Seoane-Romero JM, Vázquez-Mahía I, Seoane J, Varela-Centelles P, Tomás I, López-Cedrún JL. Factors related to late stage diagnosis of oral squamous cell carcinoma. Med Oral Patol Oral Cir Bucal. 2012; 17: 35-40.

9. Pinheiro SM, Cardoso JP, Prado FO. Oral Cancer Knowledge and Diagnosis among Dentists from the City of Jequiei, Bahia. Rev Bras Canc. 2010; 56: 195-205.

10. Dib LL, Souza RS, Tortamano N. Evaluation of the knowledge about oral cancer among undergraduate dental students of different units at University Paulista. Rev Inst Cienc Saude. 2005; 23: 287-95.

11. Brazil. Ministry of Education. National Council of Education. Resolution $\mathrm{CNE} / \mathrm{CES}$. Board of Higher Education. National Curriculum Guidelines for Undergraduate Dentistry. Official Federal Gazette; 2002 Mar 4. 
12. Brazil. National Institute for Educational Studies and Research Anísio Teixeira. Census of higher education: 2011 - technical summary. Brasilia: INEP; 2013. 114p.

13. Uti OG, Fashina AA. Oral cancer education in dental schools: knowledge and experience of Nigerian undergraduate students. J Dent Educ. 2006; 70:676-80.

14. de-Azevedo-Vaz SL, Vasconcelos KF, Rovaris K, Ferreira NP, Haiter Neto F. A survey on dental undergraduates' knowledge of oral radiology. Braz J Oral Sci. 2013; 12: 109-13.

15. Scully C, Porter S. Oral cancer. West J Med. 2001; 174: 348-51.

16. Scully C. Oral cancer aetiopathogenesis; past, present and future aspects. Med Oral Patol Oral Cir Bucal. 2011; 16: 306-11.

17. Radoi L, Paget-Bailly S, Guida F, Cyr D, Menvielle G, Schmaus A, et al. Family history of cancer, personal history of medical conditions and risk of oral cavity cancer in France: the ICARE study. BMC Cancer. 2013; 13 : 560-9.

18. Garavello W, Foschi R, Talamini R, La Vecchia C, Rossi M, Dal Maso L, et al. Family history and the risk of oral and pharyngeal cancer. Int J Cancer. 2008; 122: 1827-31.

19. Foulkes WD, Brunet JS, Kowalski LP, Narod SA, Franco EL. Family history of cancer is a risk factor for squamous cell carcinoma of the head and neck in Brazil: A case-control study. Int J Cancer. 1995; 63: 769-73.

20. Silva SD, Hier M, MlynarekA, Kowalski LP, Alaoui-Jamali MA. Recurrent oral cancer: current and emerging therapeutic approaches. Front Pharmacol. 2012; 30: 149-56. 